\title{
Pure Cerium Dioxide Preparation for use as Spectrochemical Standard and Analysed by Inductively Coupled Plasma Mass Spectrometry (SF ICP-MS)
}

\author{
Carlos A. da S. Queiroz ${ }^{*, a}$, Walter R. Pedreira ${ }^{*, b, c}$, Alcídio Abrão ${ }^{a}$, Soraya M. R. da Rocha ${ }^{a}$, \\ Mari E. de Vasconcellos ${ }^{a}$, José A. Seneda ${ }^{a}$, Christina A. L. G. de O. Forbicini ${ }^{a}$, \\ Geraldo R. Boaventura ${ }^{b}$ and Márcio M. Pimentel ${ }^{b}$ \\ ${ }^{a}$ Instituto de Pesquisas Energéticas e Nucleares (IPEN/CNEN-SP), 05508-900 São Paulo-SP, Brazil \\ ${ }^{b}$ Instituto de Geociências, Universidade de Brasília, 70910-900 Brasília-DF, Brazil \\ ${ }^{c}$ Fundação Jorge Duprat Figueiredo de Segurança e Medicina do Trabalho (FUNDACENTRO),
} 05409-002 São Paulo - SP, Brazil

Ao longo dos anos, o Instituto de Pesquisas Energéticas e Nucleares (IPEN/CNEN-SP) tem realizado diversas pesquisas na produção de Terras Raras (RE) de alta pureza. A metodologia apresentada neste trabalho refere-se à produção econômica e de baixo custo de óxido de cério. $\mathrm{O}$ cério produzido pode ser utilizado como um padrão espectroquímico. A obtenção desse padrão está associada à precipitação fracionada pelo sistema $\mathrm{RECl}_{3} / \mathrm{NH}_{4} \mathrm{OH} / \mathrm{Ar} / \mathrm{H}_{2} \mathrm{O}_{2}$, para enriquecer o óxido de cério de $90 \%$ a 99,99\% em $\mathrm{CeO}_{2}$. O controle de qualidade do padrão produzido é feito através da técnica da espectrometria de massas com fonte de plasma (ICP-MS) e confirmado pela técnica da ativação de nêutrons. Os valores das impurezas de Terras Raras no óxido, em ppm são: La(36), $\operatorname{Pr}(19), \operatorname{Nd}(161), \operatorname{Sm}(11), \operatorname{Eu}(5,3), \operatorname{Gd}(113), \operatorname{Tb}(89), \operatorname{Dy}(2), \operatorname{Ho}(0,05), \operatorname{Er}(1), \operatorname{Tm}(<0,05), \operatorname{Yb}(11)$, Lu(19) e Y(2,1), respectivamente. Os valores encontrados das impurezas são comparados aos padrões internacionais e confirmam o alto nível de pureza do óxido de cério produzido no IPEN.

For several years, IPEN/CNEN-SP has been working in the separation of the Rare Earth (RE) elements. A simple and economic procedure for the purification of technical grade cerium concentrate is described. The highly pure cerium dioxide is designed to be used as spectrochemical standard. It is obtained by association of the fractional precipitation technique, in the system $\mathrm{RECl}_{3} / \mathrm{NH}_{4} \mathrm{OH} /$ Air/ $\mathrm{H}_{2} \mathrm{O}_{2}$, to enrich the cerium up to $90 \%$ and then it is upgraded by ion exchange technique to $99.99 \% \mathrm{CeO}_{2}$. The quality control warranty was accomplished by inductively coupled mass spectrometry (ICP-MS) and neutron activation analysis. The collected values for the accompanying Rare Earth elements in a $\mathrm{CeO}_{2}$ sample are the following (ppm): $\mathrm{La}(36), \operatorname{Pr}(19), \mathrm{Nd}(161), \mathrm{Sm}(11)$, $\mathrm{Eu}(5.3), \mathrm{Gd}(113), \mathrm{Tb}(89), \operatorname{Dy}(2), \operatorname{Ho}(0.05), \operatorname{Er}(1), \mathrm{Tm}(<0.05), \mathrm{Yb}(11), \mathrm{Lu}(19)$ and $\mathrm{Y}(2.1)$, respectively. The purity of this cerium oxide is comparable to the international spectrographic standards.

Keywords: cerium dioxide, spec pure standard, rare earth fractionations, ICP-MS, neutron activation

\section{Introduction}

Researchers at IPEN/CNEN-SP have been working, for several years, with the individual separation of Rare Earth (RE) elements, aiming to assist, with the obtained products, an internal demand in other research areas. ${ }^{1-6}$ Making use of the gained experience in Rare Earth (RE) fractionation and in obtaining pure oxides, work is in progress to prepare some spectrochemically pure oxides to serve as standards. The starting RE concentrates come from the industrial exploitation of the Brazilian monazites. Until quite recently NUCLEMON

*e-mail: cqueiroz@ipen.br, walter.pedreira@fundacentro.gov.br
Ltd. was the producer of mixed Rare Earth chlorides, the bulk of the production being exported. NUCLEMON supplied to the authors some Rare Earth concentrates, especially cerium fractions, light Rare Earth fractions and heavy Rare Earth fractions. Cerium dioxide is getting more and more importance nowadays as an efficient component of polishing powder. Brazil has been a producer for the local applications for various glass substrates, lens and general optics, as well as TV screens. The raw material was a Rare Earth chloride free of thorium and uranium and decontaminated from the natural radioisotopes by lead sulfide precipitation followed by barium sulfate precipitation. Russia is today an important 
producer of polishing powder based upon the Rare Earth material, including cerium dioxide. ${ }^{7,8}$ The use of cerium dioxide as promoter for nickel based catalysts for steam reforming of methane ${ }^{9}$ and as oxygen storage component in automotive three-way catalysts has been studied. ${ }^{9}$ The preparation of spectrochemically pure cerium oxide involves two steps. Starting from Rare Earth chloride mixtures, supplied by NUCLEMON, the cerium is separated using the $\mathrm{NH}_{4} \mathrm{OH} /$ Air/ $\mathrm{H}_{2} \mathrm{O}_{2}$ system for the selective oxidation of cerium (III) to $\mathrm{Ce}(\mathrm{IV})$, and obtained as $90-95 \% \mathrm{CeO}_{2}$. The enriched cerium fractions were upgraded via ion exchange technology. Using the mini pilot already installed the work is scheduled to prepare other pure Rare Earth oxides. A wide analytical program is under development for the determination of traces of Rare Earths in the pure Rare Earth oxides using ICP-MS. ${ }^{10}$

\section{Experimental}

\section{Reagents and materials}

Mixed Rare Earth chlorides: stock solution $100 \mathrm{~g} \mathrm{~L}^{-1}$ of $\mathrm{RE}_{2} \mathrm{O}_{3}$. Natural mixed Rare Earth chlorides, having the following composition and manufactured industrially from the Brazilian monazites, were supplied by NUCLEMON, São Paulo.

Table 1. Brazilian mixed rare earth chlorides

\begin{tabular}{lr}
\hline Element & \% Oxide $\pm \sigma$ \\
\hline $\mathrm{Ce}$ & $47.0 \pm 1.0$ \\
$\mathrm{La}$ & $24 \pm 1.0$ \\
$\mathrm{Nd}$ & $18.5 \pm 1.0$ \\
$\mathrm{Pr}$ & $4.5 \pm 1.0$ \\
$\mathrm{Sm}$ & $3.5 \pm 0.5$ \\
$\mathrm{Y}$ and Heavy RE & $3.0 \pm 1.0$ \\
\hline
\end{tabular}

Cationic ion exchanger: Bayer S-100, 50-100 mesh, ammonium form. Ammonium salt of ethylenediaminetetraacetic acid, stock solution $300 \mathrm{~g} \mathrm{~L}^{-1}$ of EDTA. Hydrogen peroxide $30 \%$, commercial grade. Set-up for the hydrolysis and oxidation of cerium: hot plate, 4-litter glass reactor with electrical stirrer, pump for admission of air into the ammonium hydroxide solution for $\mathrm{NH}_{3}$ stream supply and thermometer. Four acrylic columns (5 $\mathrm{cm}$ i.d. $x 100 \mathrm{~cm}$ height). Volume of resin used: 2L each column.

\section{Equipment}

For the quantification of the REEs a sector-field inductively coupled plasma mass spectrometer (SF ICPMS), Element, from Finningan MAT (Bremen, Germany) was used (Table 2).
Table 2. SF ICP-MS operating conditions. Plasma conditions and Mass Spectrometer settings

\begin{tabular}{lc}
\hline Plasma power & $1.250 \mathrm{~kW}$ \\
Cooling gas flow & $14 \mathrm{~L} \mathrm{~min}^{-1}$ \\
Auxiliary gas flow & $0.85 \mathrm{~L} \mathrm{~min}^{-1}$ \\
Nebulizer gas flow & $0.91 \mathrm{~L} \mathrm{~min}-1$ \\
Nebulizer & Meinhard \\
Spray Chamber & Scott type \\
Sample orifice, Pt & $1.0 \mathrm{~mm}$ \\
Conical Skimmer orifice & Pt, $0.75 \mathrm{~mm}$ \\
Resolution & 300 \\
Points per peak & 30 \\
Scan mode & E-Scan and B-Scan \\
\hline
\end{tabular}

\section{Separation of cerium from mixed Rare Earth chlorides}

The separation of cerium was accomplished directly from the mixed Rare Earth chlorides by the hydrolyticoxidation process. Cerium (III) was oxidized to cerium (IV) by the controlled introduction of hydrogen peroxide. The acidity liberated by the hydrolytic process was continuously neutralized by the $\mathrm{NH}_{3}$ stream generated by compressed air injected into the $1 \mathrm{~mol} \mathrm{~L}^{-1} \mathrm{NH}_{4} \mathrm{OH}$ solution and bubbled directly into the RE chlorides solution. The initial $\mathrm{pH}$ of this solution was 4. During the separation of the cerium oxide precipitate the temperature was maintained at $60{ }^{\circ} \mathrm{C}$. Hydrogen peroxide was admitted at a rate of $0.2 \mathrm{~mL} \mathrm{~min}^{-1}$. Precipitation of each $\mathrm{CeO}_{2}$ batch was carried out in four hours and the precipitate was separated out by vacuum filtration. The precipitate $\left(\mathrm{CeO}_{2} 90 \%\right)$ was dissolved with hot $1: 1 \mathrm{HNO}_{3}$. The cerium nitrate solution was then adjusted to $10 \mathrm{~g} \mathrm{~L}^{-1}$ by dilution prior to introduction onto the ion exchanger.

\section{Final cerium purification}

Starting with the above prepared cerium nitrate solution (>90\% $\mathrm{Ce}_{2}$ ) a feeding solution of $10 \mathrm{~g} \mathrm{RE}_{2} \mathrm{O}_{3} \mathrm{~L}^{-1}$ was prepared by dilution with deionized water. This solution was percolated through a cationic exchanger system consisting of four columns connected in series. Before loading the Rare Earth nitrates, the cationic resin, initially in the $\mathrm{H}^{+}$form, was conditioned with ammonium hydroxide and rinsed with water. The resin was loaded with $c a .215 \mathrm{~g}$ $\mathrm{RE}_{2} \mathrm{O}_{3}$ (the system can be operated with $500 \mathrm{~g}$ Rare Earth oxides) and eluted with EDTA $0.01 \mathrm{~mol} \mathrm{~L}^{-1}, \mathrm{pH} 4.0$.

\section{Analytical experiment}

The separation and purification of cerium were confirmed using a simple and well-established test for this element. To a small filtrate aliquot a few drops of 1:1 $\mathrm{NH}_{4} \mathrm{OH}$ were added and the hydroxides precipitated. The solution was warmed 
and then a few drops of $\mathrm{H}_{2} \mathrm{O}_{2}$ were added. A characteristic yellow-orange color indicated the presence of cerium. This procedure was very helpful during the resin loading and elution. The cerium (IV) hydrolytic precipitate was separated by vacuum filtration. Aliquots of this precipitate were fired directly to the oxides using an electrical furnace, at $600{ }^{\circ} \mathrm{C}$. The oxide was dissolved and cerium assayed by iodometry. ${ }^{11}$ Total Rare Earth concentrations in the filtrate, depleted in cerium, were analyzed after their conversion to nitrates, precipitation with oxalic acid and subsequent calcination to the oxides. Cerium in this oxide was also assayed by iodometry. ${ }^{11}$ The final cerium oxide samples, purified by the process described above, were analyzed for the other accompanying Rare Earths as contaminants by ICP-MS and neutron activation analyzes (NAA). For neutron activation analyzes the oxides were irradiated directly in the IEA-R1 Nuclear Reactor, S.Paulo. ${ }^{12}$

\section{Results and Discussion}

Usually for an experienced analyst the visual inspection of the cerium oxide gives some information about its purity. The highly pure cerium oxide has a clear cream color. When contaminated with traces of praseodymium, for instance, the cerium oxide acquires a dark-yellow-orange color. This test was helpful during the fractionation by the elution of the Rare Earths from the resin. The contamination of the cerium oxide by lanthanum is difficult to be observed visually, because the lanthanum oxide is white.
Table 3. Sequential elution of Rare Earth fractions with $0.01 \mathrm{~mol}$ $\mathrm{L}^{-1}$ EDTA, pH 4.0

\begin{tabular}{lcccc}
\hline Fraction \# & EDTA $(\mathrm{L})$ & time $(\mathrm{h})$ & $\mathrm{\Sigma R}_{2} \mathrm{O}_{3}(\mathrm{~g})$ & $\mathrm{CeO}_{2}(\%)$ \\
\hline $\mathrm{Ce}-1$ & 14.3 & 74 & 0.75 & 1.9 \\
$\mathrm{Ce}-2$ & 19.8 & 67 & 2.07 & 3.4 \\
$\mathrm{Ce}-3$ & 19.4 & 78 & 3.17 & 46.6 \\
$\mathrm{Ce}-4$ & 19.4 & 64 & 5.17 & 95 \\
$\mathrm{Ce}-5$ & 16.0 & 67 & 8.22 & 98 \\
$\mathrm{Ce}-6$ & 38.0 & 192 & 15.57 & $\geq 99$ \\
$\mathrm{Ce}-7$ & 29.0 & 168 & 23.77 & $\geq 99$ \\
$\mathrm{Ce}-8$ & 20.0 & 120 & 33.07 & $\geq 99$ \\
$\mathrm{Ce}-9$ & 42.0 & 216 & 56.28 & $\geq 99$ \\
$\mathrm{Ce}-10$ & 39.5 & 168 & 81.28 & $\geq 99$ \\
$\mathrm{Ce}-11$ & 32.0 & 168 & 101.68 & $\geq 99$ \\
$\mathrm{Ce}-12$ & 50.0 & 240 & 138.68 & $\geq 99$ \\
$\mathrm{Ce}-13$ & 25.5 & 120 & 159.58 & $\geq 99$ \\
$\mathrm{Ce}-14$ & 50.0 & 120 & 200.68 & $\geq 99$ \\
$\mathrm{Ce}-15$ & 20.0 & 70 & 10.68 & $\geq 99$ \\
\hline
\end{tabular}

Table 3 displays the results of a typical fractionation experiment by cationic ion exchanger using the described column setup (four columns in series). The resin was loaded with $215 \mathrm{~g}$ of total Rare Earth and eluted with $0.01 \mathrm{~mol}$ $\mathrm{L}^{-1}$ EDTA at $\mathrm{pH}$ 4.0.

Table 4 shows the results of minor Rare Earths as contaminants of the various batches of pure cerium oxide determined by the ICP-MS. ${ }^{10}$ As a reference the first sample corresponds to an imported spec pure cerium oxide. Cerium in all samples was assayed by the iodometric method. ${ }^{8}$ Table 5 details NAA, ${ }^{9}$ the results of some Rare Earth contaminants of one representative cerium oxide (admixture of various batches).

Table 4. Minor Rare Earth elements $\left(\mu \mathrm{g} \mathrm{g}^{-1}\right)$ in $\mathrm{CeO}_{2}$ samples by ICP-MS. $\mathrm{n}=5$

\begin{tabular}{|c|c|c|c|c|c|c|c|}
\hline Sample & $\mathrm{La}$ & $\operatorname{Pr}$ & $\mathrm{Nd}$ & $\mathrm{Sm}$ & $\mathrm{Eu}$ & $\mathrm{Gd}$ & $\mathrm{Tb}$ \\
\hline $\mathrm{Ce}-5$ & 266 & 1200 & 3505 & 148 & 5.7 & 304 & 94 \\
\hline Ce-6 & 95 & 6600 & 785 & 50 & 5.3 & 162 & 86 \\
\hline $\mathrm{Ce}-7$ & 64 & 1996 & 343 & 133 & 6.9 & 176 & 92 \\
\hline $\mathrm{Ce}-8$ & 51 & 55 & 310 & 29 & 5.1 & 141 & 87 \\
\hline $\mathrm{Ce}-10$ & 36 & 19 & 161 & 11 & 5.3 & 113 & 89 \\
\hline $\mathrm{Ce}-11$ & 33 & 15 & 123 & 9 & 4.7 & 109 & 85 \\
\hline Ce-12 & 37 & 15 & 116 & 11 & 5.3 & 120 & 88 \\
\hline Ce-13 & 41 & 18 & 93 & 6.3 & 5.1 & 126 & 84 \\
\hline Ce-14 & 58 & 17 & 135 & 13 & 5.7 & 131 & 89 \\
\hline $\mathrm{Ce}-15$ & 8200 & 17 & 145 & 12 & 5.2 & n.d. & 89 \\
\hline Sample & Dy & Ho & $\mathrm{Er}$ & $\mathrm{Tm}$ & $\mathrm{Yb}$ & $\mathrm{Lu}$ & $\mathrm{Y}$ \\
\hline $\mathrm{Ce}-5$ & 21 & 0.6 & 0.6 & 0.1 & 23.7 & 2 & 146 \\
\hline $\mathrm{Ce}-6$ & 22 & 0.5 & 0.5 & 0.04 & 20 & 1.9 & 24 \\
\hline $\mathrm{Ce}-7$ & 31 & 1 & 1 & 0.2 & 23.5 & 2 & 225 \\
\hline $\mathrm{Ce}-8$ & 13 & 0.5 & 0.5 & 0.08 & 24 & 2.1 & 197 \\
\hline $\mathrm{Ce}-10$ & 2 & 0.05 & 0.05 & n.d. & 21 & 1.9 & 2.1 \\
\hline $\mathrm{Ce}-11$ & 3 & 0.08 & 0.8 & n.d. & 19.3 & 2 & n.d. \\
\hline $\mathrm{Ce}-12$ & 1.3 & 0.04 & 0.4 & n.d. & 16.4 & 1.8 & 4.5 \\
\hline $\mathrm{Ce}-13$ & 7.5 & 1.9 & 1.9 & 0.04 & 20.4 & 2 & 3.5 \\
\hline $\mathrm{Ce}-14$ & 3 & 0.1 & 0.1 & 0.05 & 18 & 2 & 2.7 \\
\hline $\mathrm{Ce}-15$ & 11 & 0.5 & 0.5 & 0.04 & 21 & 1.9 & 13 \\
\hline
\end{tabular}

n.d. -not determined. 
Table 5. Determination of RE traces in cerium oxide by neutron activation analysis

\begin{tabular}{cc}
\hline Element & $(\%)$ \\
\hline $\mathrm{Nd}$ & $<0.02$ \\
$\mathrm{Eu}$ & $<0.005$ \\
$\mathrm{Yb}$ & $<0.006$ \\
$\mathrm{Lu}$ & $<0.02$ \\
$\mathrm{~Tb}$ & $<0.05$ \\
$\mathrm{Sc}$ & $<0.0002$ \\
\hline
\end{tabular}

\section{Conclusions}

The purification procedure can be scaled up to semiindustrial level. This simplifies the achievement of pure $\mathrm{RE}$ elements fractions without the trouble of recovering EDTA from the processes that use the retaining ion $(\mathrm{Cu}-$ EDTA and Zn-EDTA complexes), as widely mentioned in the literature. The authors describe in this paper a method successful for the purification of Rare Earths by ion exchanger chromatography without the use of a retaining ion.

Using this simple and economic procedure it is possible to purify cerium starting with the mixture of natural Rare Earth chlorides. Using neutron activation analysis and ICPMS, traces of other Rare Earth elements can be determined at very low levels in the pure cerium oxide.

Although, the use of the Inductively Coupled Plasma Mass Spectrometry (ICP-MS) technique for the analysis of trace elements in pure Rare Earth fractions is still very expensive, this instrumental analytical method is the most powerful tool for the quantification of these impurities in high pure materials. In this case, especially for cerium oxide, Certificate Reference Materials (CRM) and high pure IPEN`s material, present some advantages for elemental trace analysis, such as high sensitivity, selectivity and low detection limits, when compared with other analytical techniques.

\section{Acknowledgments}

We thank to IPEN/CNEN-SP, CNPq, FINATEC and UnB for research grants.

\section{References}

1. Mucillo, E. N. S.; Ávila, D. M.; Cer. Int. 1999, 25, 345.

2. Ávila, D. M.; Mucillo E.N.S.; Thermochim. Acta 1995, 256, 391.

3. Ávila, D. M.; Mucillo, E. N. S.; J. Mat. Sci. Lett. 1997, 16, 685.

4. Gomes, L.; Vieira, M. M. F.; Baldochi, S. L.; Lima, N. B.; Novak, M. A.; Vieira Jr, N. D.; Morato, S. P.; J. Appl. Phys. 1998, 63, 5040.

5. Zezell, D. M.; Cecchini, S. C. M.; Eduardo, C. P.; Matsumoto, W.; Nogueira, J. R.; Vieira, N. D.; Morato, S. P.; J. Clin. Laser Med. Surg. 1995, 13, 283.

6. Ranieri, I. M.; Baldochi, S. L.; Santos, A. M.; Gomes, L.; Courrol, L.; Tarelho, W.; Barreta, J. R.; Costa, G. E.; Nogueira, N.; Wetter, D. M.; Zezell, D. M.; Vieira Jr, N. D.; Morato, S. P.; J. Crys. Growth. 1996, 166, 423.

7. Kosynkin, V. D.; Ivanov, E. N.; Kotrekhov, V. A; Shtuza, M. G.; Kardapolov, A .V.; Mat. Sci. Forum 1999, 315, 179.

8. Praharso, L .M.; Trimm, D. L.; Mat. Sci. Forum 1999, 315, 187.

9. Muraki, H.; Zyang, G.; Mat. Sci. Forum. 1999, 315, 194.

10. Pedreira, W. R.; Sarkis, J. E. S.; Queiroz, C. A. S.; Rodrigues, C.; Tomiyoshi, I. A.; Abrão, A.; J. Solid St. Chem. 2003, 171, 3.

11. Queiroz, C. A. S.; Abrão, A.; ACIESP Pub. 1989, 68, 157.

12. Saiki, M.; Lellis, L.O.; IPEN Pub. 1988, Jul., 173.

Received: October 13, 2004 Published on the web: September 15, 2005

FAPESP helped in meeting the publication costs of this article. 